\title{
Cervical metastasis of gingival carcinoma misdiagnosed as branchiogenic carcinoma, a rare entity - report of a case and review of literature
}

Qingjia Sun, Mingxing Chen, Yuxin Sun, Xi Chen, Hongjun Xu, Lingjun Rong, Qiong Wu and Dongdong Zhu*

\begin{abstract}
Background: A cervical cystic mass is associated with a number of pathologies that present with similar symptoms. These conditions are difficult to differentiate using fine-needle aspiration (FNA), ultrasound (US), computed tomography (CT) and magnetic resonance imaging (MRI). Another dilemma in the differential diagnosis of cervical cystic masses is due to the controversies associated with the existence of branchiogenic carcinoma (BC). BC is an extremely rare disease that must be differentiated from other conditions presenting with cervical cystic masses, especially cystic metastasis from occult primary lesions.
\end{abstract}

Case presentation: We present a case report of a right cervical cystic metastasis from a significantly small squamous cell carcinoma primary gingival lesion misdiagnosed as BC by histopathology. A 62-year-old female presented with a painless progressively enlarging cervical mass at the anterior edge of the sternocleidomastoid muscle in the right submandibular region. Preoperative MRI and US revealed a well-defined cystic round mass. Postoperative histological examination indicated BC. Positron emission tomography/computed tomography (PET/ CT) revealed high 18F-FDG (18F 2-fluoro-2-deoxy-D-glucose) uptake in surgical regions with a SUV (standard uptake value) max 4.0 and ipsilateral nasopharynx with a SUVmax 4.4, without any distant metastasis. Pathologic results revealed nasopharyngeal lymphadenosis. Considering the low incidence of $B C$ and the limitation of diagnosis in one institution, the patient was referred to another hospital. Physical examination detected a significantly small neoplasm ( $\sim 3 \mathrm{~mm}$ diameter) in the right lower gingiva. Histopathological examination of the neoplasm revealed a well-differentiated squamous cell carcinoma. Surgery, including a partial mandibulectomy and modified neck dissection (neck level I-V and submental lymph nodes) were undertaken. Postoperative histopathological results revealed a well-differentiated squamous cell carcinoma of right lower gingiva and two metastatic lymph nodes in the 18 lymph nodes of level II. A month later, recurrence occurred in the right cervical level II. The patient was placed on postoperative concurrent chemo-radiotherapy and supportive care. The patient suffered from cachexia and survived for only six months after surgery.

Conclusions: In cases of cervical cystic masses that appear after the age of 40, clinicians should bear in mind that occult primary lesions should be excluded and examination of the gingiva should be undertaken. PET/CT has a limited role in identifying small occult primary lesions and a comprehensive physical examination must be carefully performed.

Keywords: Gingival cervical cystic metastatic carcinoma, Branchiogenic carcinoma, Cystic metastasis from occult primary lesions, Nasopharyngeal carcinoma

\footnotetext{
*Correspondence: asd830915@163.com

Department of Otorhinolaryngology Head and Neck Surgery, The

China-Japan Union Hospital of Jilin University, Xiantai Street 126, Changchun

130033, China
} 


\section{Background}

The majority of head and neck carcinomas are squamous cell carcinomas with a high incidence of recurrence and metastasis $[1,2]$. Survival is reduced if metastasis has occurred [3, 4]. Cervical lymph node metastases of head and neck carcinomas have been extensively studied, with the majority developing as solid masses [1, 5]. However, the preoperative differential diagnosis of cervical cystic metastasis is challenging, especially in carcinoma of unknown primary (CUP), which account for 3-9\% of all head and neck carcinomas [6]. Cervical cystic masses are associated with a number of conditions that often present similar symptoms, including branchial cleft cysts (BCC), branchiogenic carcinomas (BC) and cervical cystic CUP [7-9]. However, these conditions are difficult to differentiate from each other by fine-needle aspiration (FNA), ultrasound (US), computed tomography $(\mathrm{CT})$ and magnetic resonance imaging (MRI) [8]. Among these lesions, $\mathrm{BCC}$ is the most common, which results from the incomplete obliteration of the embryonal branchial apparatus and is lined by stratified squamous epithelium histologically $[10,11]$. Although $\mathrm{BC}$ are associated with cystic masses, there is much controversy surrounding such a diagnosis $[12,13] . \mathrm{BC}$ is an extremely rare disease, which was initially believed to be a malignant transformation of the epithelium within the branchial cyst walls [10]. In 1950, Martin et al. [14] proposed strict diagnostic criteria for BC, which were later modified by Khafif et al. in 1989 [15]. At present, however, diagnosis of $\mathrm{BC}$ remains a topical debate. The lack of multi-center analysis and inadequate number of samples are contributory factors that impede precise diagnosis.

The key method for $\mathrm{BC}$ diagnosis is dependent on surgical excisional biopsy. Although FNA has a high accuracy $(>90 \%)$ for the diagnosis of cervical solid masses, false-negative rates for cystic masses are as high as 38$63 \%$ [16]. Small cancerous lesions may remain unidentified using 18F 2-fluoro-2-deoxy-D-glucose (18 F-FDG) positron emission tomography/computed tomography (PET/CT) [17] and hence limit its role in the differentiation between cervical cystic CUP and BC. Therefore, cervical cystic CUP may easily be misdiagnosed as $\mathrm{BC}$ [8] or BCC, preoperatively [18].

In the present study, we report a case of right cervical cystic metastasis from a significantly small squamous cell carcinoma primary gingival lesion, misdiagnosed as $\mathrm{BC}$ by histopathology and nasopharyngeal carcinoma by PET/CT. The misdiagnosis impacted on the prognosis and quality of life of the patient. Squamous cell carcinoma of the gingiva is less common than carcinoma of other tissues in the oral cavity; however, there are no differences in initial symptoms [19]. The management of oral squamous cell carcinoma is not straightforward and may involve surgery, radiotherapy, or a combination of both $[19,20]$. However, recommended therapeutic approaches for the management of cervical CUP are surgical neck dissection, radiotherapy or neck dissection and comprehensive radiotherapy in combination [6]. By contrast, treatment of $\mathrm{BC}$ has been undertaken by both excising a single mass alone [21], or by complete surgical excision followed by adjunct radiotherapy [22-24]. The management of the malignancy therefore depends on distinct guidelines. Therefore, accurate preoperative diagnosis is essential for treatment planning and improving outcomes and prognoses.

\section{Case presentation}

A 62-year-old female was referred to the Department of Otorhinolaryngology Head and Neck Surgery of the China-Japan Union Hospital of Jilin University, China, in March 2016. The patient presented with a two-month history of a painless and progressively enlarged unilateral mass on the right side of the neck. Clinical examination revealed a submandibular swelling located at the anterior edge of the sternocleidomastoid muscle on the right side of neck. The female had no history of smoking or alcohol consumption. Endoscopic examination, including laryngoscopy, rhinoscopy, and endotoscopy, did not detect any pathology in the nasal cavity, nasopharynx, oropharynx, hypopharynx or larynx. Ultrasonic examination revealed a cystic hypoechoic change, approximately $1.5 \mathrm{~cm}$, in the right submandibular region. MRI of neck revealed a well-defined round mass $(\sim 1.5 \times 1.7 \times 1.6 \mathrm{~cm})$ proximal to the anterolateral side of the right submandibular gland. The mass had a well-distributed intermediate signal at $\mathrm{T}_{1} \mathrm{WI}$ and a high signal at $\mathrm{T}_{2} \mathrm{WI}$, with an obvious enhancement of the peripheral wall in contrast-enhanced $\mathrm{T}_{1} \mathrm{WI}$ (Fig. 1). These images strongly suggested a cervical cystic lesion with the characteristics of a benign mass.

Based on the detailed history, clinical examination and investigations, surgical excision of the lesion was planned. The provisional diagnosis of $\mathrm{BCC}$ and treatment options were explained to the patient and informed written consent was obtained for the proposed treatment. The case study and treatment plan was approved by the institutional review board and ethics committee of The ChinaJapan Union Hospital of Jilin University.

The mass was excised completely, using a right-neck lateral approach under general anesthesia. During surgery, the lesion was highly pigmented and appeared as a welldefined ovoid cystic mass with little adhesion to marginal mandibular branch of the facial nerve. Frozen section analysis indicated a diagnosis of squamous cell carcinoma with a significant possibility of $\mathrm{BC}$ rather than a metastatic lymph node. We, therefore, chose conservative resection of the lesion. Postoperative histopathologic examination 


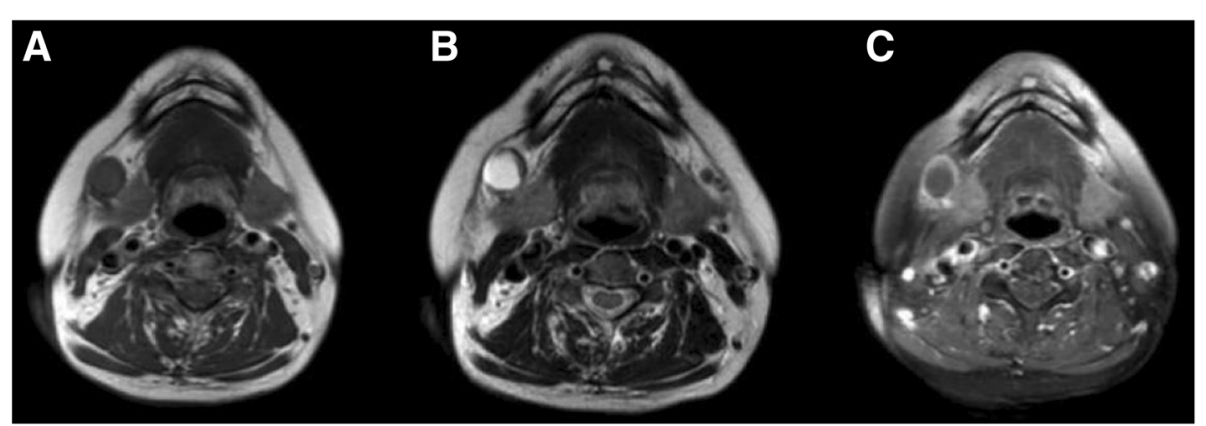

Fig. 1 Preoperative MRI of the neck: a well-defined round mass proximal to the anterolateral side of the right submandibular gland, a $T_{1} W l$ revealed a well-distributed intermediate signal; $\mathbf{b} \mathrm{T}_{2} \mathrm{Wl}$ revealed a high signal; and $\mathbf{c}$ contrast-enhanced $\mathrm{T}_{1} \mathrm{Wl}$ revealed an obvious enhancement of the peripheral wall

was performed by two senior pathologists independently under double-blind conditions. The resected mass appeared to be cystic, overlapped by lymphoid tissues. The internal surface was lined by thin-layered squamous epithelium with severe dysplasia and had characteristic features of $\mathrm{BC}$ (Fig. 2). Considering the low incidence of BC, PET/CT was performed to differentiate cervical metastasis of unknown primary lesion. The results of the scan showed high FDG uptake in surgical regions with SUVmax 4.0 and homolateral nasopharynx with SUVmax 4.4, without any evidence of distant metastasis (Fig. 3), which suggested nasopharyngeal malignancy. For diagnosis of nasopharyngeal carcinoma, the patient agreed to undergo nasopharyngeal biopsy twice by two senior otolaryngologists. All histopathologic examinations revealed lymphadenosis. Considering the limited resources of the primary institution, the patient was referred to a specialist hospital, The Cancer Institute \& Hospital, Chinese Academy of Medical Sciences. In an outpatient clinic, physical examination was performed and showed a significantly small neoplasm $(\sim 3 \mathrm{~mm}$ at its largest

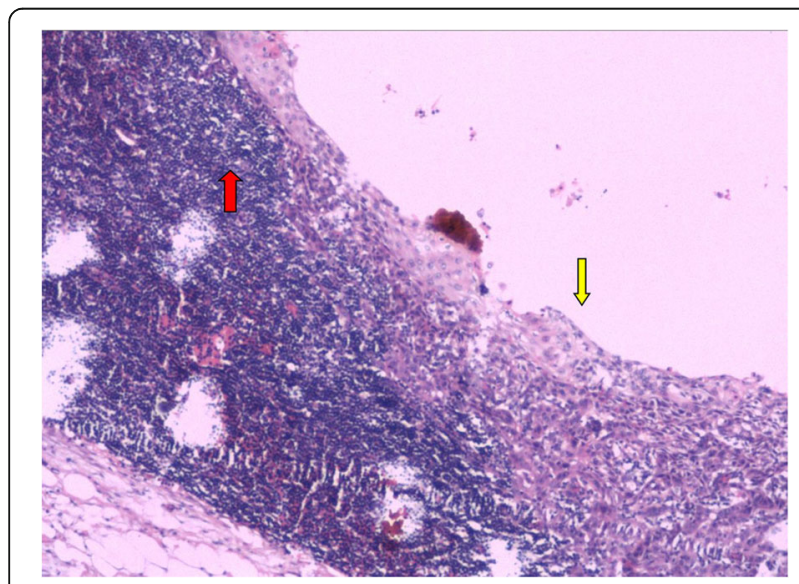

Fig. 2 The histopathologic examination showed that the resected mass of lateral neck appeared as a cystic structure overlapped by lymphoid tissue (red arrow) with an internal surface lined by squamous cell carcinoma epithelium (yellow arrow) (HE $\times 40$ ) diameter) in the right lower gingiva. Initial pathological diagnosis of the small neoplasm was conducted using a forceps biopsy technique and revealed a well-differentiated squamous cell carcinoma. Following detailed study of the case and investigations, a final diagnosis of gingival carcinoma with neck metastasis was made. Surgery including partial resection of the mandible and modified neck resection (neck level I-V and submental lymph nodes) was performed. Postoperative pathology examination revealed a well-differentiated squamous cell carcinoma of the right lower gingiva and two metastatic lymph nodes of the 18 lymph nodes of level II. A month later, recurrence occurred in the right cervical level II and the patient underwent postoperative concurrent chemo-radiotherapy. The patient became cachectic and lived for only six months.

\section{Discussion}

In the present case, we shared the experience of the misdiagnosis between cervical metastasis of gingival carcinoma and BC. One possible reason for misdiagnosis may be due to our lack of experience of cervical cystic disease. Cervical cystic metastasis remains a challenging issue for preoperative diagnosis, with an incidence ranging from $33 \%$ to $62 \%$ [10]. Cervical cystic diseases may be associated with $\mathrm{BCC}, \mathrm{BC}$, cervical cystic CUP, cystic necrotic schwannoma, lymph node with necrotic granulomatous inflammation, lymphangioma, venous malformation, lymphoma with cystic degeneration, metastatic papillary thyroid carcinoma $[10,25]$, or malignant ectopic thyroid glands $[26,27]$. The diagnosis of $\mathrm{BC}$ remains controversial and excluding other potential similar presentations, such as cervical cystic CUP, is paramount. In 1950, Martin et al. [14] proposed strict diagnostic criteria for $\mathrm{BC}$ as follows:

1. Cervical tumors must be located along the anterior border of the sternocleidomastoid muscle from the tragus to the clavicle. 


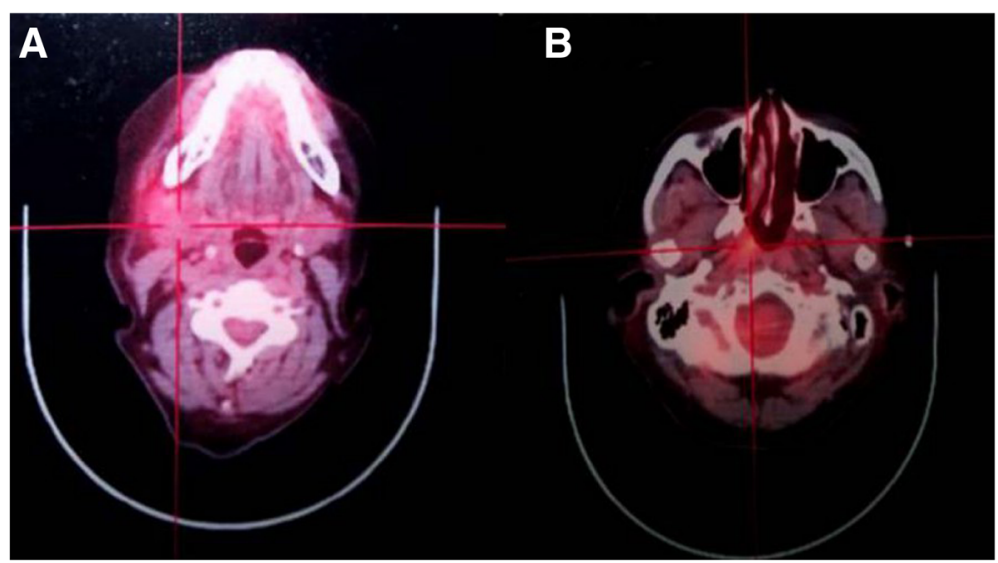

Fig. 3 PET/CT revealed high FDG uptake in a surgical regions and $\mathbf{b}$ ipsilateral nasopharynx

2. The histological appearance of the growth must be consistent with an origin in the tissues present in the branchial vestiga.

3. The patient must be followed up for at least five years without appearance of any occult primary tumors.

4. Histological evidence of the developing cancer must be found in the wall of an epithelial cyst situated in the lateral aspect of the neck.

However, many authors argue that it is difficult to meet the third criterion, because the duration of diagnosis is too long for therapy or patients who underwent postoperative radiotherapy, which may affect appearance of occult primary [28]. In 1989, Khafif et al. [26] modified these criteria and attenuated the role of follow up and emphasized the absence of an identifiable primary as well as clear histological identification of the nature of the tumor. To date, the incidence of $\mathrm{BC}$ is extremely rare [16].

The second reason for misdiagnosis may be due to the lack of comprehensive physical examinations and over dependence on radiological examinations, such as PET/ CT. The present case, presenting with $\mathrm{BC}$ histologically, was finally diagnosed as cervical cystic metastasis with occult primary originating from gingiva. A similar case has been reported by Zhang et al. [29], where a case of upper cervical cystic mass appearing as BC histologically was found. It had metastasized from the gingiva and was diagnosed through PET/CT. To the best of our knowledge, the presenting case is the second report of cervical cystic metastasis from occult gingiva primary lesion. In contrast, the approximately $3 \mathrm{~mm}$ primary lesion of the present case is too small to detect through $\mathrm{PET} / \mathrm{CT}$, compared to the $1 \mathrm{~cm}$ lesion in the Zhang et al. report [29]. The role of PET/CT for the detection of CUP has been well described [30]. However, Ferris et al. [17] concluded that PET/CT has a limited role in smaller primary lesions, and the findings could be misleading. Consistent with Ferris et al. [17], the right nasopharynx of the case exhibited high uptake of FDG and the result of the biopsy showed chronic inflammation, as inflammatory lesions can have a high SUV value [31]. In our report, the final detection of occult primary lesions was dependent on oral physical examination. Therefore, careful physical examination should not be ignored in the search for occult primary lesions.

Squamous cell carcinoma of the gingiva is an extremely rare disease with a female predominance [32]. In comparison with other oral squamous cell carcinoma, the cause of gingiva squamous cell carcinoma is rarely associated with smoking, ultraviolet radiation, oncogenic viruses and infection [32]. The treatment of the disease includes surgery and/or radiotherapy, depending on the tumor stage [33]. Gingival squamous cell carcinoma has a variable clinical presentation that allows the disease to be easily misdiagnosed as a benign tumor or other inflammatory responses [34]. It has been reported that prognosis of gingival squamous cell carcinoma is dependent on volume [35]; therefore, early detection is crucial for improving prognosis. It has been reported that $72-90 \%$ of cervical squamous cell carcinoma metastases are from Waldeyer's ring (base of tongue, palatine tonsils and nasopharynx) $[18,36,37]$, and other sites, including the larynx, hard palatine, and thyroid gland, are rare [10]. Zhang et al. [8] reported two cases with cervical cystic masses, which were diagnosed as malignant after surgical excision. The final diagnosis was nasopharyngeal carcinoma with neck metastasis determined by biopsy. Papillary carcinoma of ectopic thyroid glands arising from BCC could appear as solitary cervical cystic mass $[26,38]$. It has been suggested that cervical cysts in patients older than 40 years of age should raise the possibility of metastases [18], which is consistent with the 
current case. The present case and Zhang et al.'s report [29] suggests that the oral cavity including the gingiva must be checked in patients suffering from suspected cervical cystic malignancy.

\section{Conclusions}

The incidence of $\mathrm{BC}$ is extremely rare. In cases of cervical cystic masses that appear clinically after the age of 40 , clinicians should bear in mind that occult primary lesions should be excluded and the examination of the gingiva should not be ignored. PET/CT has a limited role in the identification of small occult primary lesions. Hence, comprehensive physical examinations must be carefully performed to explore lesions at the earliest stage.

\section{Abbreviations}

18F-FDG: 18F 2-fluoro-2-deoxy-D-glucose; BC: Branchiogenic carcinoma; BCC: Branchial cleft cyst; CT: Computed tomography; CUP: Carcinoma of unknown primary; FNA: Fine-needle aspiration; MRI: Magnetic resonance imaging; PET/CT: Positron emission tomography/computed tomography; US: Ultrasound

\section{Acknowledgments}

This manuscript has been proofread by Medjaden Bioscience Limited.

\section{Funding}

Not applicable.

\section{Availability of data and materials}

The datasets used and/or analysed during the current study available from the corresponding author on reasonable request.

\section{Authors' contributions}

DZ developed the conception and design of the study, as well as the acquisition of data, analysis and interpretation of data as the corresponding author and gave final approval for this version to be published. QS contributed to the histological examination of malignant lesions, and was a major contributor in writing the manuscript. $M C$ was involved in drafting the manuscript. The other authors (YS, HX, XC, RJ and QW) participated in the surgery carried out in this case and revised the manuscript critically for important intellectual content. All authors read and approved the final manuscript.

\section{Ethics approval and consent to participate}

The case study and treatment plan was approved by the institutional review board and ethics committee of The China-Japan Union Hospital of Jilin University.

\section{Consent for publication}

Written informed consent was obtained for the patient according to federal and institutional guidelines. A copy of the consent form could be available for review by the Editor of this journal.

\section{Competing interests}

The authors declare that they have no competing interests.

\section{Publisher's Note}

Springer Nature remains neutral with regard to jurisdictional claims in published maps and institutional affiliations.
Received: 22 November 2016 Accepted: 20 November 2017

Published online: 28 November 2017

\section{References}

1. Shah JP, Medina JE, Shaha AR, Schantz SP, Marti JR. Cervical lymph node metastasis. Curr Probl Surg. 1993;30(3):1-335.

2. XL W, Tu Q, Faure G, Gallet P, Kohler C, Bittencourt Mde C. Diagnostic and prognostic value of circulating tumor cells in head and neck Squamous cell carcinoma: a systematic review and meta-analysis. Sci Rep. 2016;6:20210.

3. Shen ZS, Li JS, Chen WL, Fan S. The latest advancements in selective neck dissection for early stage oral Squamous cell carcinoma. Curr Treat Options in Oncol. 2017;18(5):31.

4. Sharma D, Koshy G, Grover S, Sharma B. Sentinel lymph node biopsy: a new approach in the management of head and neck cancers. Sultan Qaboos Univ Med J. 2017;17(1):e3-e10.

5. van den Brekel MW, Stel HV, Castelijns JA, Nauta JJ, van der Waal I, Valk J, Meyer CJ, Snow GB. Cervical lymph node metastasis: assessment of radiologic criteria. Radiology. 1990;177(2):379-84.

6. Zhuang SM, XF W, Li JJ, Zhang GH. Management of lymph node metastases from an unknown primary site to the head and neck (review). Mol Clin Oncol. 2014;2(6):917-22.

7. Devaney KO, Rinaldo A, Ferlito A, Silver CE, Fagan JJ, Bradley PJ, Suarez C. Squamous carcinoma arising in a branchial cleft cyst: have you ever treated one? Will you? J Laryngol Otol. 2008;122(6):547-50.

8. Z Zhang GZ, Liu ZL, Gong JS, Cheng ZQ, Ke C. Cystic metastatic nasopharyngeal carcinoma presenting as branchial cleft cyst: report of two cases and review of the literature. J Oral Maxillofac Surg. 2014;72(11):2366-74.

9. Sai-Guan L, Min-Han K, Kah-Wai N, Mohamad-Yunus MR. Nasopharyngeal carcinoma with cystic cervical metastasis masquerading as Branchial cleft cyst: a potential pitfall in diagnosis and management. Iran J Otorhinolaryngol. 2017;29(91):117-20.

10. Bradley PT, Bradley PJ. Branchial cleft cyst carcinoma: fact or fiction? Curr Opin Otolaryngol Head Neck Surg. 2013;21(2):118-23.

11. Lin YC, Fang SY, Huang RH. Branchiogenic squamous cell carcinoma: a case report. Int J Oral Maxillofac Surg. 2004;33(2):209-12.

12. Jereczek-Fossa BA, Casadio C, Jassem J, Luzzatto F, Viale G, Bruschini R, Chiesa F, Orecchia R. Branchiogenic carcinoma-conceptual or true clinicopathological entity? Cancer Treat Rev. 2005;31(2):106-14.

13. Goldenberg D, Sciubba J, Koch WM. Cystic metastasis from head and neck squamous cell cancer: a distinct disease variant? Head Neck. 2006;28(7):633-8.

14. Martin $\mathrm{H}$, Morfit $\mathrm{HM}$, Ehrlich $\mathrm{H}$. The case for branchiogenic cancer (malignant branchioma). Ann Surg. 1950;132(5):867-87.

15. Khafif RA, Prichep R, Minkowitz S. Primary branchiogenic carcinoma. Head Neck. 1989;11(2):153-63

16. Layfield LJ, Esebua M, Schmidt RL. Cytologic separation of branchial cleft cyst from metastatic cystic squamous cell carcinoma: a multivariate analysis of nineteen cytomorphologic features. Diagn Cytopathol. 2016;44(7):561-7. doi:10.1002/dc.23461. Epub 2016 Mar 9

17. Ferris RL, Branstetter BF, Nayak JV. Diagnostic utility of positron emission tomography-computed tomography for predicting malignancy in cystic neck masses in adults. Laryngoscope. 2005;115(11):1979-82.

18. Gourin CG, Johnson JT. Incidence of unsuspected metastases in lateral cervical cysts. Laryngoscope. 2000;110(10 Pt 1):1637-41.

19. Gomez D, Faucher A, Picot V, Siberchicot F, Renaud-Salis JL, Bussieres E, Pinsolle J. Outcome of squamous cell carcinoma of the gingiva: a follow-up study of 83 cases. J Craniomaxillofac Surg. 2000;28(6):331-5.

20. Swiecicki PL, Malloy KM, Worden FP. Advanced oropharyngeal squamous cell carcinoma: pathogenesis, treatment, and novel therapeutic approaches. World J Clin Oncol. 2016;7(1):15-26.

21. Nakano A, Mishima K, Katase N, Ueyama Y. A case of squamous cell carcinoma arising from branchial cleft cyst. J Oral Maxillofac Surg. 2015; 73(4):781-5.

22. Girvigian MR, Rechdouni AK, Zeger GD, Segall H, Rice DH, Petrovich Z Squamous cell carcinoma arising in a second branchial cleft cyst. Am J Clin Oncol. 2004;27(1):96-100.

23. Chauhan A, Tiwari S, Pathak N. Primary branchiogenic carcinoma: report of a case and a review of the literature. J Cancer Res Ther. 2013;9(1):135-7.

24. Roche JP, Younes MN, Funkhouser WK, Weissler MC. Branchiogenic carcinoma of a first branchial cleft cyst. Otolaryngol Head Neck Surg. 2010; 143(1):167-8. 168 e161 
25. Pietarinen-Runtti P, Apajalahti S, Robinson S, Passador-Santos F, Leivo I, Makitie AA. Cystic neck lesions: clinical, radiological and differential diagnostic considerations. Acta Otolaryngol. 2010;130(2):300-4.

26. Kushwaha JK, Sonkar AA, Goel MM, Gupta R. Papillary carcinoma of thyroid arising from ectopic thyroid tissue inside branchial cleft cyst: a rare case. BMJ Case Rep. 2012;2012. doi:10.1136/bcr.02.2012.5783.

27. Karras $S$, Anagnostis $P$, Noussios $G$, Pontikides $N$. Thyroid papillary carcinoma arising in ectopic thyroid tissue within a branchial cleft cyst. BMJ Case Rep. 2013;2013:bcr2013009312.

28. Bhanote M, Yang GC. Malignant first branchial cleft cysts presented as submandibular abscesses in fine-needle aspiration: report of three cases and review of literature. Diagn Cytopathol. 2008;36(12):876-81.

29. Zhang XX, Zhao K, Zhou SH, Wang QY, Liu JH, ZJ L. Metastatic squamous cell carcinoma of the gingiva appearing as a solitary branchial cyst carcinoma: diagnostic role of PET/CT. Int J Clin Exp Pathol. 2014;7(10):7059-63.

30. Majchrzak E, Cholewinski W, Golusinski W. Carcinoma of unknown primary in the head and neck: the evaluation of the effectiveness of (18)F-FDG-PET/ CT, own experience. Rep Pract Oncol Radiother. 2015;20(5):393-7.

31. Balink H, Tan SS, Veeger NJ, Holleman F, van Eck-Smit BL, Bennink RJ, Verberne HJ. (1)(8)F-FDG PET/CT in inflammation of unknown origin: a costeffectiveness pilot-study. Eur J Nucl Med Mol Imaging. 2015;42(9):1408-13.

32. Bharanidharan R, Dineshkumar T, Raghavendhar K, Kumar AR. Squamous cell carcinoma of the gingiva: a diagnostic enigma. J Oral Maxillofac Pathol. 2015;19(2):267.

33. Bark R, Mercke C, Munck-Wikland E, Wisniewski NA, Hammarstedt-Nordenvall L. Cancer of the gingiva. Eur Arch Otorhinolaryngol. 2016;273(6):1335-45.

34. Kumari PS, Kumar GP, Bai YD, Reddy EY. Gingival squamous cell carcinoma masquerading as an aphthous ulcer. J Indian Soc Periodontol. 2013;17(4): 523-6.

35. Gupta R, Debnath N, Nayak PA, Khandelwal V. Gingival squamous cell carcinoma presenting as periodontal lesion in the mandibular posterior region. BMJ Case Rep. 2014;2014. doi:10.1136/bcr-2013-202511.

36. Regauer S, Mannweiler S, Anderhuber W, Gotschuli A, Berghold A, Schachenreiter J, Jakse R, Beham A. Cystic lymph node metastases of squamous cell carcinoma of Waldeyer's ring origin. Br J Cancer. 1999; 79(9-10):1437-42.

37. Thompson LD, Heffner DK. The clinical importance of cystic squamous cell carcinomas in the neck: a study of 136 cases. Cancer. 1998;82(5):944-56.

38. Ruhl DS, Sheridan MF, Sniezek JC. Papillary thyroid carcinoma in a Branchial cleft cyst without a thyroid primary: navigating a diagnostic dilemma. Case Rep Otolaryngol. 2013;2013:405342.

\section{Submit your next manuscript to BioMed Central and we will help you at every step:}

- We accept pre-submission inquiries

- Our selector tool helps you to find the most relevant journal

- We provide round the clock customer support

- Convenient online submission

- Thorough peer review

- Inclusion in PubMed and all major indexing services

- Maximum visibility for your research

Submit your manuscript at www.biomedcentral.com/submit

CBiomed Central 